\title{
Exploring the Intra-Metropolitan Dynamics of the London Office Market
}

\author{
Paper Presented at the Pacific-Rim Real Estate Society Annual \\ Conference, Auckland, New Zealand, January 2006
}

\author{
Simon Stevenson, Cass Business School, City University \\ Corresponding Author: Faculty of Finance, Cass Business School, City University, \\ 106 Bunhill Row, London EC1Y 8TZ, UK. Tel: +44-20-7040-5215. \\ E-mail: s.stevenson-2@city.ac.uk \\ $\&$ \\ Tony McGough, Cass Business School, City University
}

\begin{abstract}
This paper explores the relationships between key sub-markets in the Central London office market. The paper models the intra-metropolitan dynamics and examines how sub-markets influence and impact upon one another. Set within a rent adjustment framework the modelling approach highlights the key linkages and allows a broader examination of the overall dynamics of the London office market. The results highlight the position of the West End as the prime submarket within Central London and also the impact of the development of the Docklands submarket on the Central London office market.
\end{abstract}

Preliminary Draft, January 2006 


\section{Exploring the Intra-Metropolitan Dynamics of the London Office Market}

\section{1: Introduction}

Previous examinations of office market dynamics have tended to concentrate on either national or metropolitan markets. However, many metropolitan markets contain distinct submarkets that may behave in a fragmented manner. Fragmentation can be of two types. The first is spatial fragmentation that refers to locational features. The second is structural fragmentation, whereby differences occur due to property specific issues. While a number of papers have in recent years examined submarket behaviour, the majority contain purely descriptive statistics or have analysed submarket dynamics within a hedonic framework. Fuerst (2005) for example, examines submarket dynamics in the New York market in a hedonic framework. The current paper relies upon a different approach and one that does not require the use of individual property data and a hedonic modelling approach. The model adopted is an extension of the Hendershott et al. (2002) error-correction specification of a rental adjustment process and is empirically tested using data from the London office market. The model allows the incorporation of disequilibrium in other submarkets into the rent adjustment process for each of the submarkets in term.

The London market is of interest for a number of reasons. Firstly, it is one of the largest office markets globally, both in terms of square footage and also in investment terms. Secondly, the market also contains a number of distinct submarkets. Thirdly, in the development of the docklands office market in the early nineties it is an example of a major market that has witnessed substantial structural change with the potential to observe impacts upon submarkets across the city. Existing studies of the London market have however examined either the overall metropolitan market (Wheaton et al., 1997) or the specific City of London market (Hendershott et al., 1999 and Stevenson \& McGrath, 2003). However, as already noted London contains a number of quite distinct sub-markets. The two primary submarkets in central London are the City of London and the West End. In addition, there are two smaller submarkets in Midtown and the docklands market. London's submarkets are also key examples of where spatial and structural forms of fragmentation are hard to separate. These differences relate both to tenant mix and also to property specific issues relating to 
office specifications. These can come through in terms of divergences in the dynamics of the different markets as Jackson et al. (2005) illustrate between the City and West End markets. It should be noted that some locations can often be preferred to others dependent on the position in the economic cycle that the markets are in. This has been analysed at the regional level by several papers looking at other factor issues (see for example Johnston et al., 2000 and Henneberry et al., 2003). This paper however, is concentrating on the pure market interaction effects. The remainder of the paper is laid out as follows. Section 2 presents the modelling framework used in this paper. Section 3 reports the empirical findings while Section 4 provides concluding comments.

\section{2: Modelling Framework}

The framework used in this paper is based on the error-correction specification of the rent adjustment process proposed by Hendershott et al. (2002). The model is based on the rent adjustment model utilised by Hendershott (1996) and Hendershott et al. (1999) ${ }^{1}$. However, Hendershott et al. (2002) note that this original specification has similarities to an error-correction model in that rents are assumed to adjust to the divergences from the long-term equilibrium. They therefore specify a reduced form model assuming that the demand for space is a function of the real effective rent and employment, which in this case is acting as a proxy for occupational demand. The base form model can be represented as:

$$
\ln R=\ln \gamma_{0}+\gamma_{1} \ln E+\gamma_{2} \ln (1-v)+\gamma_{3} \ln S U+u_{t}
$$

Where $R$ is the deflated effective rent, $E$ is employment, $v$ is the vacancy rate and $S U$ is stock. The use of employment as the sole proxy for occupational demand is justified in the considerable degree of empirical evidence highlighting its presence as a key driving force in office demand. In the context of the London market this has been illustrated in papers such as Wheaton et al. (1997), Hendershott et al. (1999, 2002) and Stevenson \& McGrath (2003). As with all error-correction frameworks, if the

\footnotetext{
${ }^{1}$ McGough \& Tsolacos (2004) compare both the Wheaton et al. (1998) and Hendershott et al. (1999) models for London, finding the Hendershott model to be the better performer, although with a low explanatory power.
} 
residual from this equation is stationary then the levels of the variables are cointegrated as they are integrated to the order $I(1)$. The short-run error-correction model can therefore be represented as follows:

$$
\Delta \ln R=\alpha_{0}+\alpha_{1} \Delta \ln E+\alpha_{2} \Delta \ln (1-v)+\alpha_{3} \Delta \ln S U+\alpha_{4} u_{t-1}
$$

The lagged residual from the long-run log-level model acts as a measure of the divergence of the rent from its long-term equilibrium. While this reduced form model is highly useful in the examination of single markets it may be problematic to use in the context of markets with multiple distinct office markets that may influence each other. In the context of the current study it would be dubious to solely examine a single submarket within London without attention being placed upon the interactions present. While these interactions will naturally influence variables such as the effective rent and vacancy rate the proposed model allows an explicit examination of the reaction to disequilibrium in other submarkets. A key example that will be examined in this study concerns the impact of the development of the docklands market and its impact upon in particular the City of London market. The innovation in the current paper that allow the examination of multiple submarkets within a single framework and leads to the incorporation of pricing issues in other markets is based on recent work in a housing context by McQuinn (2004) and Stevenson \& Young (2005). The long-run model is estimated for each of the four submarkets in Central London, namely, the City, West End, Midtown and Docklands. However, in the errorcorrection specification rather than just include the error-correction term from the appropriate submarket the model is extended to include multiple error-correction terms. For example, in the specification for the West End, the error-correction terms for the City, Midtown and Docklands markets are also included in the estimation.

$$
\begin{aligned}
& \Delta \ln R=\alpha_{0}+\alpha_{1} \Delta \ln E+\alpha_{2} \Delta \ln (1-v)+\alpha_{3} \Delta \ln S U \\
& +\alpha_{4} u_{1, t-1}+\alpha_{5} u_{2, t-1}+\alpha_{6} u_{3, t-1}+\alpha_{7} u_{4, t-1}
\end{aligned}
$$

The data used in this paper was provided by CB Richard Ellis. The two primary reasons behind the use of a single data provide were that firstly all of the necessary information required could be obtained and secondly that different London agencies 
adopt slightly different submarket definitions. The data provided by CBRE also included details of rent-free periods, thereby allowing the estimation of effective rents. These were estimated in a manner similar to that adopted in Hendershott et al. (1999, 2002). All of the models are estimated over the period 1990-2004. This is considerably shorter than that used in previous models of the London market. While data for the two primary submarkets, City and West End, was available from the early seventies, it was felt important to model the impact of the development of the docklands market in the late eighties and early nineties.

\section{Table 1: Unit Root Tests}

\begin{tabular}{lcc}
\hline \multicolumn{2}{c}{ Levels } & First Differences \\
\hline \multicolumn{2}{l}{ Panel A: Effective Real Rents } & \\
\hline City of London & -1.9645 & $-4.0385^{* *}$ \\
West End & -2.5143 & $-3.9102^{* *}$ \\
Midtown & -2.0512 & $-3.7926^{* *}$ \\
Docklands & -1.4841 & $-6.3417^{* * *}$ \\
\hline Panel B: Vacancy Rates & \\
\hline City of London & -1.1312 & $-3.8261^{* *}$ \\
West End & -1.1522 & $-5.4368^{* * *}$ \\
Midtown & -1.9349 & $-3.6638^{* *}$ \\
Docklands & -0.8205 & $-4.4054^{* * *}$ \\
\hline Panel C: Stock & & $-5.7497^{* * *}$ \\
\hline City of London & -2.1581 & $-8.5704^{* * *}$ \\
West End & -1.5614 & $-5.7113^{* * *}$ \\
Midtown & -2.1983 & $-6.1517^{* * *}$ \\
\hline Docklands & -1.6095 & $-6.0889^{* * *}$ \\
\hline Panel D: Employment & & \\
\hline Employment & -2.3919 & \\
\hline
\end{tabular}

Notes: Table 1 reports the Augmented Dickey-Fuller unit root tests. * indicates significance at $10 \%, * *$ at $5 \%$ and $* * *$ at $1 \%$. In each case the variables are shown to be $I(1)$.

\section{3: Empirical Findings}

Prior to reporting the results from the long-run and short-run models it is important to test for stationarity in the series in question. Table 1 reports Augmented Dickey-Fuller unit root tests for effective rents, vacancy rates and stock for each of the submarkets and for the employment variable. In all cases the variables are $I(1)$. The results for the long-run models are contained in Table 2. In all cases the variables are of the anticipated sign and are significant at conventional levels. The adjusted R-square's are relatively low in a number of cases and in particular in the case of the City market. This is particularly so in comparison to the results reported in the Hendershott et al. (2002) study, but is to be expected if one considers the results of the modelling by 
McGough \& Tsolacos (2004). The residuals were tested for stationarity in line with the two-step Engle-Granger cointegration test with significant results obtained across all four models implying cointegration. This therefore provides justification for the adoption of an error-correction framework in the short-run modelling.

Table 2: Long-Run Level Models

\begin{tabular}{lcccc}
\hline & City of London & West End & Midtown & Docklands \\
\hline Constant & -28.5101 & -25.3713 & -92.4307 & -50.5535 \\
& $(-1.6325)$ & $\left(-5.4140^{* * *}\right)$ & $\left(-8.7705^{* * *}\right)$ & $\left(-7.7418^{* * *}\right)$ \\
Employment & 3.9631 & 4.1998 & 5.3406 & 6.3813 \\
& $\left(1.8455^{*}\right)$ & $\left(4.40667^{* * *}\right)$ & $\left(14.8269^{* * *}\right)$ & $\left(7.6001^{* * *}\right)$ \\
Vacancy Rate & -6.5985 & -13.4769 & -10.8950 & -0.9545 \\
& $\left(-3.6746^{* * *}\right)$ & $\left(-7.0803^{* * *}\right)$ & $\left(-16.6630^{* * *}\right)$ & $\left(-4.5576^{* * *}\right)$ \\
Stock & -6.0424 & -10.7228 & -10.1022 & -0.4902 \\
& $\left(-1.8376^{*}\right)$ & $\left(-7.2518^{* * *}\right)$ & $\left(-11.6723^{* * *}\right)$ & $\left(-2.8113^{* * *}\right)$ \\
\hline Adjusted R ${ }^{2}$ & 0.2863 & 0.5851 & 0.8456 & 0.7230 \\
\hline
\end{tabular}

Notes: Table 2 reports the results from the long-run log level model shown in Equation (1). The figures in parentheses are t-statistics. ${ }^{*}$ indicates significance at $10 \%,{ }^{* *}$ at $5 \%$ and ${ }^{* * *}$ at $1 \%$.

Table 3: Error-Correction Models

\begin{tabular}{lcccc}
\hline & City of London & West End & Midtown & Docklands \\
\hline Constant & -0.0200 & -0.0239 & -0.0218 & 0.0014 \\
& $(-0.9066)$ & $\left(-2.6554^{* *}\right)$ & $\left(-2.3916^{* *}\right)$ & $(0.0705)$ \\
Employment & 0.8043 & 2.4204 & 0.2634 & 2.7914 \\
& $(0.4738)$ & $\left(2.9428^{* * *}\right)$ & $(0.3032)$ & $\left(1.9317^{*}\right)$ \\
Vacancy Rate & -2.4254 & -4.8306 & -3.0341 & 0.4781 \\
& $(-1.2263)$ & $\left(3.7977^{* * *}\right)$ & $\left(-3.0508^{* * *}\right)$ & $(0.5423)$ \\
Stock & -2.1599 & -4.5321 & -3.1737 & -0.2837 \\
& $(00.6767)$ & $\left(-3.5758^{* * *}\right)$ & $\left(1.7847^{*}\right)$ & $(-0.5573)$ \\
ECM Term & -0.1624 & -0.0943 & -0.1699 & -0.2262 \\
& $\left(-2.5563^{* *}\right)$ & $\left(-1.9034^{*}\right)$ & $(-2.0569 * *)$ & $\left(-2.4358^{* *}\right)$ \\
\hline Adjusted R & 0.1892 & 0.4069 & 0.2766 & 0.1768 \\
\hline Notes: Table 3 reports the results from the original Hendershott et al. (2002) error-correction model \\
displayed in Equation (2). The figures in parentheses are t-statistics. * indicates significance at 10\%, ** \\
at 5\% and *** at 1\%.
\end{tabular}

The implied price and income elasticities are relatively consistent across all four submarkets although interesting divergences are apparent. The price elasticities are 0.15, $-0.07,-0.09$ and -1.05 for the City, West End, Midtown and Docklands markets respectively. The corresponding income elasticities are $0.60,0.31,0.49$ and 6.69. The relatively low elasticities for the West End market highlight its position as the key prime market within London. The slightly higher elasticities obtained for the midtown market highlight its position as a sub-prime market. The higher elasticities for the City and in particular the Docklands markets highlight in part the impact of the development of the docklands as an alternative to the City. The large increase in space 
available for the financial services industry, and the clear marketing of the Docklands as an alternative to the City would naturally lead to higher sensitivities in both markets.

The results from the initial short-term error-correction model are reported in Table 3. A number of issues are worth noting with regard to the results obtained. The first is in respects similar to those noted concerning the implied elasticities obtained from the long-run model in that there are notable differences between the West End and Midtown markets on the one hand and the City and Docklands markets on the other. For the West End and Midtown markets the majority of the coefficients are both of the anticipated sign and significant, the exceptions being the employment variable for Midtown and the error-correction term for the West End. Legal firms occupy a large proportion of the midtown market and it is therefore perhaps not surprising that it is less sensitive to general movements in service employment. The lack of significance with regard to the West End's error-correction term is again perhaps indicative of its position as the prime office market in London and the spatial constraints within that submarket. In contrast to these findings the results for the City and Docklands markets are to some extent disappointing in terms of the significance of the variables. In the City market only the error-correction term is significant, while for the docklands market the employment variable is significant together with its disequilibrium term. These findings may be due to both markets effectively chasing the same potential tenants and the impact of the supply shock that occurred as the docklands market developed. The fact that both submarkets have significant error-correction terms highlights the divergences from long-run equilibrium during the period under examination. This is understandable as the time period studied covers the rise of the Docklands.

The results for the augmented error-correction models with the inclusion of the additional ECM terms are reported in Table 4. The only difference in the reported coefficients for employment, vacancy and stock is that the employment variable for the Docklands market is no longer significant at conventional levels. The main interest is however with the results obtained for the different error-correction terms. In each case at least one of the terms from another submarket is significant, highlighting the potential usefulness of such an approach. The results also reveal possibly 
interesting patterns in the dynamics. The City market's term has a significant impact in each case. This implies that the disequilibrium observed within the City market had a significant impact on each of the other submarkets. This in all likelihood highlights its importance and also its relative size within the overall central London market. Given these factors the City is often seen as a barometer of how London itself is doing. In contrast to the initial model the West End's term is significant when the West End itself is modelled. However, the lack of significance of the West End's ECM term in relation to the Midtown market is perhaps surprising, given that the two are spatially contiguous. However, differences in tenant mix may explain this finding. The results with regard to the Midtown market are in line with expectations given its relative size.

Table 4: Augmented Error-Correction Models

\begin{tabular}{lcccc}
\hline & City of London & West End & Midtown & Docklands \\
\hline Constant & -0.0224 & -0.0253 & -0.0230 & 0.0099 \\
& $(-1.0057)$ & $\left(-2.7615^{* * *}\right)$ & $\left(-2.5877^{* *}\right)$ & $(0.5128)$ \\
Employment & 0.1233 & 2.2058 & 0.2587 & 2.2846 \\
& $(0.0687)$ & $\left(2.6699^{* *}\right)$ & $(0.2738)$ & $(1.4679)$ \\
Vacancy Rate & -1.4047 & -4.4939 & -2.2322 & -0.1803 \\
& $(-0.6643)$ & $\left(-3.1981^{* * *}\right)$ & $\left(-2.0054^{*}\right)$ & $(-0.2054)$ \\
Stock & -1.4134 & 4.5468 & -3.5575 & -0.0998 \\
& $(-0.4341)$ & $\left(-3.3756^{* * *}\right)$ & $\left(1.9927^{*}\right)$ & $(-0.2022)$ \\
City ECM Term & -0.3404 & -0.3282 & -0.1753 & -0.2972 \\
& $(2.7059 * * *)$ & $\left(-3.2742^{* * *}\right)$ & $\left(-1.8862^{*}\right)$ & $\left(-1.8033^{*}\right)$ \\
West End ECM Term & -0.0409 & -0.1421 & -0.1052 & -0.4378 \\
& $(-0.2404)$ & $(-1.6937 *)$ & $(-1.1624)$ & $\left(-2.8638^{* * *}\right)$ \\
Midtown ECM Term & -0.2975 & 0.0795 & -0.3179 & 0.0089 \\
& $(-1.6942 *)$ & $(0.9905)$ & $\left(-4.9122^{* * *}\right)$ & $(0.0592)$ \\
Docklands ECM Term & -0.1103 & -0.1356 & -0.0927 & -0.4571 \\
& $(-0.7017)$ & $\left(-2.1762^{* *}\right)$ & $\left(-2.1876^{* *}\right)$ & $\left(-3.3378^{* * *}\right)$ \\
\hline Adjusted R ${ }^{2}$ & 0.1333 & 0.4049 & 0.2648 & 0.3073 \\
\hline
\end{tabular}

Notes: Table 4 reports the results from the augmented error-correction model displayed in Equation (3) and incorporating all four error-correction terms in each estimation. The figures in parentheses are tstatistics. ${ }^{*}$ indicates significance at $10 \%, * *$ at $5 \%$ and $* * *$ at $1 \%$.

Probably the most interesting findings relate to the Docklands market. The results when the Docklands model is estimated are in line with expectations in that both the City and West End terms are significant. The lack of significance for the Midtown market is not surprising given its relative size and importance. However, the Dockland's own ECM term has a mixed and initially counter intuitive effect upon the remaining three markets. The supply shock caused by its development has an impact upon both the West End and Midtown but not on the City market. The finding that it impacts upon the West End and Midtown highlights the impact of the vast increase in 
supply in the early nineties across the entire central London market. An addition issue is that while initially marketed as an alternative to the City, the docklands market has increasingly attracted a broader tenant mix than pure financial services. The results with regard to the City are not in line with expectations given that the City market is that most closely related in terms of tenant mix and the submarket that Docklands is the closest substitute. It is possible that the Docklands market impacted more directly upon the City through the effective rents and vacancy rates and in the medium term on supply. Therefore, the results do not necessarily imply that the Docklands market had no impact upon the City market.

\section{4: Concluding Comments}

This paper has proposed an augmented error-correction framework to model the rent adjustment process across the four primary office submarkets in Central London. The model allows for disquilibrium in each of the markets to be directly incorporated into the modelling framework for the individual markets. The results highlight the differences in the characteristics of the four submarkets. In particular, the West End market is shown to be relatively less sensitive to both fundamentals and to market dynamics in the other markets. This highlights its position as the prime submarket within central London. The impact of the development of the Docklands submarket is apparent across the entire market. 


\section{References}

Fuerst, F. (2005). A hedonic approach to analysing the volatility and cross-sectional variability of office rental rates, Paper presented at the American Real Estate Society annual meeting, Santa Fe, New Mexico.

Henneberry, J., McGough, T. and Mouzakis, F. (2003). Planning regimes and their impacts on local business rents and local and national output, Paper presented at the European Real Estate Society annual conference, Helsinki.

Hendershott, P.H. (1996). Rent adjustment and valuation in overbuilt markets: Evidence from Sydney, Journal of Urban Economics, 39, 51-67.

Hendershott, P.H., Lizieri, C.M. and Matysiak, G.M. (1999) The workings of the London office market, Real Estate Economics 27, 365-87.

Hendershott, P.H., MacGregor, B.D. and Tse, R.Y.C. (2002) Estimation of the rental adjustment process, Real Estate Economics 30, 165-84.

Jackson, C., Stevenson, S. and Watkins, C., (2005). NY-LON: Does a single crosscontinental office market exist ?, working paper, Real Estate Finance \& Investment Group, Cass Business School.

Johnston, R.J., Gregory, D., Pratt, G. and Watts, M. (2000). The dictionary of human geography, Blackwell, Oxford, $4^{\text {th }}$ ed.

Lizieri, C., Baum, A. and Scott, P. (2000). Ownership, occupation and risk: A view of the City of London office market, Urban Studies, 37, 1109-1129.

McGough T. and Tsolacos S., (2004). Modelling the demand for office space in Central London, Paper presented at the European Real Estate Society annual Conference, Milan.

McQuinn, K. (2004). A model of the Irish housing sector, Research Technical Paper 1/RT/04, Central Bank and Financial Services Authority of Ireland.

Stevenson, S. and McGrath, O. (2003). A comparison of alternative rental forecasting models: Empirical tests on the London office market, Journal of Property Research, 20, 235-260

Stevenson, S. and Young, J. (2005). An error-correction model of housing supply, working paper, Real Estate Finance \& Investment Group, Cass Business School.

Wheaton, W. (1987) The cyclical behavior of the national office market, Journal of American Real Estate and Urban Economics Association 15, 281-99.

Wheaton, W. and Torto, R. (1988) Vacancy rates and the future of office rents, Journal of American Real Estate and Urban Economics Association 16, 430-6.

Wheaton, W., Torto, R. and Evans, P. (1997) The cyclical behavior of the Greater London office market, Journal of Real Estate Finance and Economics 15, 77-92. 